Much of the book was written soon after the war, and already the methods of control that were developed then have been applied to such effect that some of the areas discussed are now malaria-free. In every area emphasis is laid on the general principles of prevention-the need to have enlightened commanders, to involve all men, and to strike a balance between environmental control and personal responsibility.

\section{H. VAughaN}

Epidemiology : Reports on Research and Teaching. Ed. by J. Pemberton. (Pp. 360; 55s.) London: Oxford University Press. 1963.

One of the features of recent progress in medicine has been the development of epidemiology, the ecology of man in terms of health and disease. Most of the published work is widely distributed in epidemiological journals and in general and specialist medical journals. There have also been a few compendia of articles on epidemiology, and this book is one of these. It contains an edited selection of papers given in Yugoslavia at a meeting of the International Epidemiological Association.

A wide variety of subjects by 39 authors has been classified into eight parts: Cancer; Diarrhoeal Diseases; Arterial Pressure; Occupational Diseases and Accidents; Neurological Disease, Anaemia and Nephropathy; Standardization of Diagnostic Techniques; Health Services; and Some Recent Developments in the Teaching of Social Medicine.

Some of the articles report recent work of the authors while others are more general; Richard Doll's 'Contribution of Epidemiology to Knowledge of Cancer' is outstanding among the latter. The sections on Neurological Disease, Anaemia and Nephropathy, Diarrhoeal Diseases, and Arterial Pressure offer good examples of geographic medicine.

The articles in Section VI show that surprising progress is being made in standardizing diagnostic techniques, important for comparative studies in the field of psychiatry. Carstairs and Wing show how this difficult subject can be advanced by the use of epidemiological methods.

Health Services have an article by Professor McKeown in which he advances his controversial views about the future of the general practitioners, and three articles from the United States of America, which are of an operational type. In the section on Social Medicine Drs. Prasad and San Martin describe some teaching efforts in India and Chile, methods adapted particularly to the rural conditions of those countries; and in the final article Dr. Stokes shows how, at the Harvard Medical School, he evaluated the teaching of family health. He found 'no effect'!

The section on Occupational Diseases and Accidents, like the other sections, is not a comprehensive or systematic survey of the work in this field. Recent work on byssinosis is well covered, and Ross A. McFarland writes on the epidemiology of industrial accidents in the United States of America. Much of this article and of others in the book has appeared previously, but nevertheless it is valuable to have a book which brings together a number of important subjects treated epidemiologically.
Readers who are not epidemiologists will find this book interesting and enlightening, and epidemiologists will in addition find it a useful source book because, even apart from the articles, there are good lists of references.

A. M. Adelstein

Paramedical Microbiology. By Stanley E. Wedberg. (Pp. 462; illustrated; 54s.) London: Chapman \& Hall. 1963.

This is apparently intended as a textbook for nurses, who are mentioned seven times in the introduction alone and repeatedly in the subsequent text. The author does not confine himself to microbiology, but ranges over a number of topics which are of interest in public health. Blood grouping occupies six pages; tobacco smoking and cancer, two. Twenty pages are devoted to food poisoning, including five pages on poisoning by chemicals and plants, but no mention of Clostridium welchii! Other omissions from the sections on pathogenic bacteria and viruses include Str. viridans, Str. faecalis, Haemophilus, E. coli, mumps, and herpes simplex. But space is wasted on non-pathogens like Gaffkya and Sarcina whose existence as clearly defined genera would be disputed by most bacteriologists.

The book is too long for an introductory textbook and suffers from repetition in its different sections. It condemns common practices, e.g. disinfection of thermometers in $70 \%$ alcohol, without suggesting an alternative.

Two admirable features are the inclusion of historical data scattered throughout the text and a glossary of microbiological terms, but even some of these are inaccurate or misleading. The book would appeal to those who enjoy a popular style ('miracle drugs', 'Achilles heel') and do not mind inaccuracies. It is printed on good quality non-shiny paper and has some very good illustrations.

\section{N. W. Preston}

Report of the Medical Research Council for the Year 1961-62. (16s. 6d.) London: H.M.S.O.

The extent of the work which is undertaken or supported by the M.R.C. may not be as generally recognized as it deserves to be. Some idea of its vastness and quality can be gained from the annual report of the Council for the year October 1961 to September 1962.

The report is presented in three parts. In the first part the work of the Council's recently formed Advisory Boards is reviewed, and matters of policy, administration, finance, and personnel are detailed. During the year four members of the Council's staff were macie Nobel Laureates; two shared the prize for chemistry and two the prize for medicine and physiology. The second part of the report consists of 11 articles on selected aspects of research ranging from the genetic code to the application of engineering techniques to medicine and biological science. The third part is made up of summaries of the work of the National Institute for Medical Research at Mill Hill, London, and of the work of the numerous research units and groups, of the external scientific staff, and of the recipients of research grants. 